\title{
Study on the Clinical Profile of Patients with Cerebral Palsy
}

\author{
Nabanita Das ${ }^{1}$, Gayatri Bezboruah ${ }^{2}$, Indira Das ${ }^{3}$ \\ Department of Pediatrics, Gauhati Medical College AndHospital.
}

\begin{abstract}
Cerebral Palsy (CP) has emerged as one of the major causes of chronic childhood disability. A cross sectional study was conducted in Inpatient and Out Patient Department of Pediatrics in GMCH, Composite Regional Centre (CRC), and also from SishuSarothi, Spastics society of Assam for a period of 1 year from July 2014 to June 2015. The aims and objectives of the study were tostudy the clinical pattern and etiological factors of Cerebral Palsy and to determine the prevalence of associated disabilities or handicaps in Cerebral Palsy.Our study population included one hundred cases of diagnosed Cerebral Palsy cases upto 12 years of age. Classification was done using modified Minear classification. Simple statistical analysis was used for percentage calculation.Spastic type was the predominant (80\%), with quadriplegic subtype being the most common (43\%). The other types were mixed type (8\%), hypotonic (7\%) and athetoid (5\%) being the least. Speech delay was the most common associated problem (76 \%) followed by microcephaly (56\%), seizures (48\%), visual defects (23\%), feeding difficulty (21\%), hearing problems (18\%), contractures and deformities (9\%) and behavioural problems (7\%) being the least. The most common etiologic risk factors were maternal age $<20$ years and $>35$ years and pregnancy induced hypertension in prenatal period; asphyxia, low birth weight and prematurity in perinatal period; and central nervous system infections and hyperbilirubinemiain the postnatal period.The clinical spectrum of $C P$ in our country may differ from that reported from the western countries. Perinatal factors were leading risk factors in CP etiology in this study. Timely diagnosis and initiation of appropriate rehabilitation programmes should be ensured.
\end{abstract}

Keywords: Cerebral Palsy, severe asphyxia, spasticity

\section{Introduction}

Disabled children are of great concern to the family as well as to the society. After eradication of polio, Cerebral Palsy (CP) has emerged as one of the major causes of chronic childhood disability in India. Cerebral Palsy has been defined as a group of permanent disorders of the development of movement and posture, causing activity limitation, that are attributed to non-progressive disturbances that occurred in the developing fetal or infant brain. The motor disorders of Cerebral Palsy are often accompanied by disturbances of sensation, perception, cognition, communication and behavior, by epilepsy, and by secondary musculoskeletal problems[1].

The worldwide prevalence of $\mathrm{CP}$ ranges from 1.5 to more than 4 per 1000 live births or children of a defined age range [2].

In India, it is estimated at around 3 cases per 1000 live births; however, being a developing country the actual figure may be much higher than probable figures. There are about 25 lakhs CP children in India as per the last statistical information [3]. The prevalence and pattern of Cerebral Palsy varies between different geographical regions, probably because of different etiological factors and different classifications used.

Since CP is a continuing problem, it is important to study and explore the causes and the newer aspects of the condition for proper understanding and management

The present study was conducted with the following aims and objectives:

- To study the clinical pattern and etiological factors of Cerebral Palsy.

- To determine the prevalence of associated disabilities or handicaps in Cerebral Palsy.

\section{Materials and methods}

Across-sectional epidemiological study was conducted in Inpatient and Out Patient Department of Pediatrics in GMCH,Composite Regional Centre (CRC) and SishuSarothi, Spastics society of Assam for a period of 1 year from July 2014 to June 2015.100 casesof diagnosed cerebral palsy up to 12 years of age were included in the study.Children with non central motor deficits were excluded. The study was approved by the Institutional Ethical Committee.

Informed consent was taken from director of SishuSarothi and CRC and also from the parents.Data collection was done by questionnaires and neurodevelopmental examination. Children were assigned to different socioeconomic strata according to Modified KuppuswamyScale.Level I was considered as upper socio 
economic status, Level II and III were together considered as middle socio economic status and level IV and V were together considered as lower socio economic status for this study.

The cases were classified based on the modified Minear's classification [4] [5]. This classification was found suitable for the study as it has classified Cerebral Palsy under physiologic, topographic and functional categories and therefore meet the aims of the present study.

A thorough history and examination was done to find out the associated handicaps in the child.Epilepsy in a child was diagnosed from history and EEG examination.Vision defect was assessed by history, clinical examination and fundoscopy. Hearing defect was assessed by history, clinical examination and BERA (Brainstem Evoked Response Audiometry).

Head circumference with $\mathrm{Z}$ score < 3 SD were considered as microcephaly. Superficial and deep sensory functions were evaluated using standard bed- side clinical methods.Others handicaps like speech defects, swallowing difficulty, behavioural disorders, contractures and deformities were determined from history and clinical evaluation of the child.

\section{Results}

The sex distribution of C.P. cases showed a male preponderance with a male: female ratio of 1.7:1 Cerebral Palsy was most often seen in the low (56\%) and the middle (39\%) socio- economic groups. Only $5 \%$ cases were observed from the upper class. The first born child $(70 \%)$ wasmost commonly affected and the prevalence decreased with increasing order of birth in this study. Delayed milestones (90\%) were the most important mode of presentation of the $\mathrm{CP}$ cases. Convulsion (38\%), inability to move one side (18\%), follow up cases $(10 \%)$ and abnormal movements $(5 \%)$ were other few modes of presentation. $8 \%$ cases gave family history of either C.P., epilepsy or mental subnormality.

Spastic Cerebral Palsy (80\%) was the largest group followed by mixed C.P.(8\%) in this study. Atonic C.P. were seen in $7 \%$ cases and athetosis constituted $5 \%$ of the total cases. Pure case of rigidity, tremor or ataxia was not encountered in this study.Among the spastic cases, quadriplegia was the major topographic group as it comprised of $43 \%$ of the total cases. Hemiplegia (22\%), diplegia (12\%), double hemiplegia (2\%) and triplegia $(1 \%)$ were obtained in decreasing order of frequency. No case of monoplegia or paraplegia was encountered in this study.

\section{Physiologic types of CP}

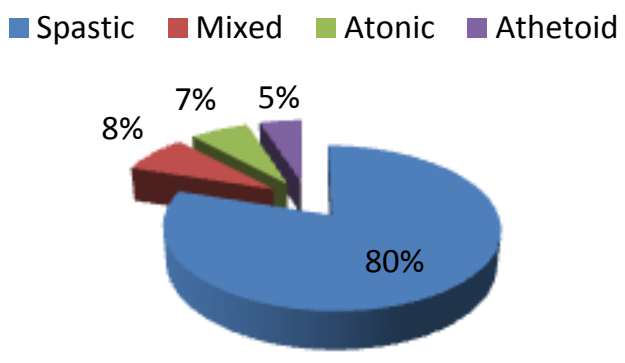

Fig 1: Pie diagram showing physiologic types of 100 cases of C.P. in the present study

Speech defect was observed in $76 \%$ cases and the spastics were most affected followed by theathetoids, atonic and mixed cases.Microcephaly was present in $56 \%$ cases and was directly proportional to the severity of involvement. Although IQ was not assessed, almost all cases with microcephaly had mental retardation too.

Epilepsy was a major handicap occurring in $48 \%$ cases and the prevalence was more in atonic $(85.7 \%)$ followed by spastic C.P.Hearing defect was present in $18 \%$ cases and athetoid C.P. was most frequently associated with it.Visual defects were present in $23 \%$ cases and spastic diplegia was most commonly associated with it.

Behavioural problems were present in $7 \%$ cases and the hemiplegic C.P. was most commonly affected. Temper tantrum, excessive dependency, hyperactiveness and marked restlessness were the commonest behavioural problems.Contractures and deformities were common in spastic C.P. $9 \%$ of the study population had this problem. Feeding difficulties were present in $21 \%$ of the total study population. Spastic double hemiplegia were most commonly affected by feeding difficulties followed by spastic quadriplegia, atonic and mixed C.P. 


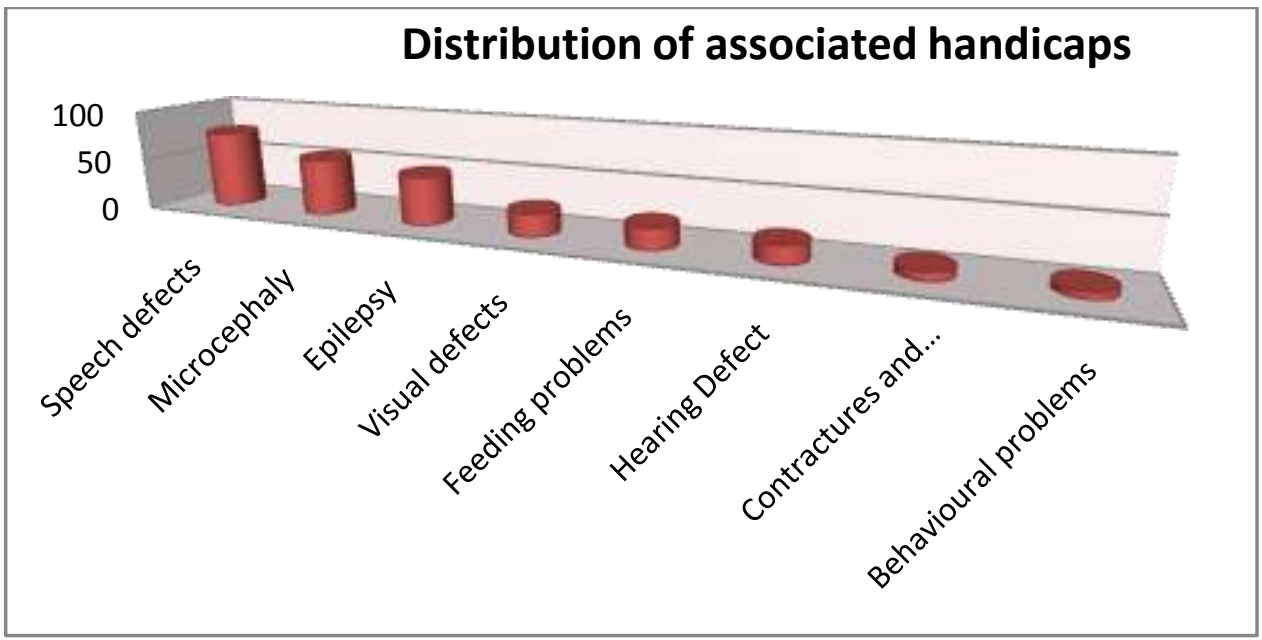

Fig2: Bar diagram showing distribution of associated handicaps

$58 \%$ of the study population were unable to carry out any useful activity (Class IV). Moderate to great limitation of activity (Class III) was present in $18 \%$ cases, Slight to moderate limitation of activity (Class II) was present in $16 \%$ cases and in $8 \%$ cases, there was no practical limitation of activity (Class I).

Among the probable prenatal etiologic factors, maternal age less than 20 years and more than 35 years was the commonest factor (17\%) followed by Pregnancy Induced Hypertension (PIH) which was present in $7 \%$ cases in the study population. Maternal infections (5\%), bleeding (4\%), Diabetes Mellitus (1\%), hypothyroidism (1\%) and cardiovascular disease $(1 \%)$ were other common causes. There was also history of consanguineous marriage in $2 \%$ cases.

Among the perinatal factors, perinatal asphyxia was found in $57 \%$ cases and difficult forceps delivery was found in $7 \%$ cases. $15 \%$ of cases were premature and $36 \%$ had low birth weight. Twin delivery was found in $4 \%$ cases. Breech delivery and transverse lie delivery was found in $2 \%$ and $1 \%$ cases respectively.

Among the post natal factors, CNS infection contributed $11 \%$ of the total cases with meningitis (4\%), encephalitis (4\%) and neonatal sepsis (3\%). Neonatal hyperbilirubinaemia was found in $14 \%$ cases.3\% cases had convulsions without fever. There was 1 case $(1 \%)$ of stroke and 1 case $(1 \%)$ of head injury leading to unconsciousness.

The etiology in $8 \%$ cases remained unknown.

Table 1: Showing distribution of the prenatal factors in the present study

\begin{tabular}{|c|c|c|}
\hline Factors & No. of cases & Percentage \\
\hline Maternal age $<20$ and $>\mathbf{3 5}$ & $\mathbf{1 7}$ & $\mathbf{1 7}$ \\
\hline Consanguinity & $\mathbf{2}$ & $\mathbf{2}$ \\
\hline Pregnancy induced Hypertension & $\mathbf{7}$ & $\mathbf{7}$ \\
\hline Bleeding & $\mathbf{4}$ & $\mathbf{5}$ \\
\hline Infections & $\mathbf{5}$ & $\mathbf{0}$ \\
\hline Trauma & $\mathbf{0}$ & $\mathbf{0}$ \\
\hline Drugs & $\mathbf{0}$ & $\mathbf{3}$ \\
\hline Others & $\mathbf{3}$ & \\
\hline
\end{tabular}

(Others included 1 case each of Diabetes Mellitus, hypothyroidism and cardiovascular disease in the mother)

Table 2: Showing distribution of the perinatal factors in the present study

\begin{tabular}{|c|c|c|}
\hline Factors & No. of cases & Percentage \\
\hline Severe Asphyxia & 57 & 57 \\
\hline Difficult forceps & 7 & $\mathbf{7}$ \\
\hline Breech & 2 & 1 \\
\hline Transverse lie & 1 & 4 \\
\hline Twins & 4 & 15 \\
\hline Preterm & 15 & 36 \\
\hline
\end{tabular}


Study On The Clinical Profile Of Patients With Cerebral Palsy

Table 3: Showing distribution of post natal factors in the present study

\begin{tabular}{|c|c|c|}
\hline Factors & No. of cases & Percentage \\
\hline Meningitis & 4 & 4 \\
\hline Encephalitis & 4 & $\mathbf{1}$ \\
\hline Head injury & 1 & 1 \\
\hline Stroke & 1 & 3 \\
\hline Convulsions & 3 & 14 \\
\hline Neonatal hyperbilirubinaemia & 14 & 3 \\
\hline
\end{tabular}

\section{Discussion}

CP can affect both genders; however boys are affected slightly higher than girls. In this current study, we observedthat 63 of our 100 cases were boys with a boy/girl ratio of 1.7:1. Consistent with these results,Johnson et al. [6] reported boy/girl ratio as 1.33 in Europe and Laisramet al. [7] reported as 1.9 in India. The most common types are the spastic types worldwide. Similarly, most of our patients (80\%) were spastic CP. However, the distribution of the clinical subtypes of spastic CP in our studydiffered from the results of western countries. In our study, $43 \%$ of our cases were spastic quadriplegia and $12 \%$ were spastic diplegia. Gowdaet al.had reported $16 \%$ cases of spastic diplegia and $71.6 \%$ cases of spastic quadriplegia which is similar to our study[8]. In European countries, studies reported 18\% -20.8\% cases of spastic quadriplegia and 40.9\%- 54.9\% cases of spastic diplegiawhich is in contrast to our studies[6] [9] [10]. The probable explanationsof this finding may be the decreased perinatal mortality of premature babies as a result of more available andequipped newborn intensive care units in western countries and observed differences in predisposing risk factorsin-between.

Among the probable etiologic factors in the present study, perinatal factors were the most prevalent. However in a few cases, more than one probable cause was taken into account, as it was difficult to pin point one etiological agent. Severe asphyxia is the leading perinatal cause of Cerebral Palsy in this study which was observed in $57 \%$ of the cases. This observation is similar to the Indian studies by done by Sharma et al (1999), Singhi et al (2013) and Gowda et al (2015)[8] [11] [12]. But studies particularly from developed countries like Nelson and Ellenberg(1986), Nelson and Grether(1999) have found that perinatal asphyxia is a much less frequent cause of Cerebral Palsy than claimed for [13] [14].

$\mathrm{CP}$ was seen in $80 \%$ of vaginal deliveries which might be due to lack of timely intervention in the perinatal period and non-availability of appropriate obstetric and postnatal care.

$15 \%$ of the cases were premature and $36 \%$ had low birth weight in this study which is similar to findings reported by Gowda et al who also found $15 \%$ cases of prematurity and $30 \%$ cases with low birth weight [8]. It has been observed in this study that most premature cases had other additional risk factors like hyperbilirubinaemia, twinning, asphyxia etc. and it is similar to the observation made by Ozmen et al (1993) [15].

Among the prenatal factors, maternal age was most common etiologic factor followed by pregnancy induced hypertension. Maternal age less than 20 years and more than 35 years was found in $17 \%$ of the cases whereasGowda et al observed it in only 7\% cases [8].The age of 15 mothers were below 20 years and 2 were above 35 years at the time of birth of the affected child in this study. Fraser reported an increased risk of pre term birth, low birth weight and small for gestational age in teenage mothers in the age group of 13 - 17 years when compared to mothers of age group of 20- 24 years [16]. Wu et al. (2006) and Thorngren-Jerneck et al (2006) reported that maternal age over 35 years doubled the risk of Cerebral Palsy [17] [18].

Among the post natal factors, in central nervous system infections, there were 3 cases of neonatal sepsis, 4 cases each of meningitis and encephalitis together constituting $11 \%$ of the total cases. This is comparable to Indian studies by Sharma et al and Gowda et al who have reported $14.9 \%$ and $12 \%$ CNS infections causing C.P. respectively [8] [11].

Hyperbilirubinaemia was accounted for $14 \%$ of the total cases and is comparable to the study by Fidan et al (2014) [19].

$8 \%$ cases in the present study were of unknown etiology which is identical to Fidan et al (2014) who reported $10 \%$ cases of unknown etiology [19]. When the distribution of etiological factors in clinical classification is assessed, it is remarkable that asphyxiaand difficult deliveries are more common in spastic quadriplegia, prematurity and low birth weight in spasticdiplegiaand neonatal hyperbiluribinemia in athetoid CP.Speech defect was the most commonly associated associated handicap in this study followed by microcephaly (56\%), epilepsy (48\%), visual defects (23\%), feeding difficulties (21\%), hearing defects (18\%), contractures and deformities $(9 \%)$ and behavioural problems (7\%).Epilepsy was most commonly found to be associated with Atonic C.P. followed by Spastic C.P. in this study. This finding is similar to Zafeiriou et al (1999) who found epilepsy in $36.1 \%$ cases with higher incidence in atonic diplegic (87.5\%) [20].

Hearing defect was most commonly associated with athetoid C.P. in this study which is similar to Fidan et al (2014)[19]. Singhi et al (2002) reported that hemiplegics had a predilection to develop behaviouralproblems and this was also encountered in this study [21].Hoffer et al reported that contractures in

\begin{tabular}{|c|c|}
\hline 55458 & www.iosriournals.org \\
\hline
\end{tabular}


Cerebral Palsy (CP) were usually in flexion at the hips and knees, and in plantar flexion at the ankles which is similar to this study [22].

There are some limitations of our study. The major limitationswere the cloudy memory of the parents and poor medical records of the cases and also the relatively small number of patients included. Hence, a long term follow up study with more cases anda comprehensive analysis of the etiologic agents would be more beneficial.

\section{Conclusions}

It was observed in this study that perinatal factors were a leading risk factors in $\mathrm{CP}$ etiology. We assume that $\mathrm{CP}$ incidence can effectively be lowered by improving the pregnancy monitoring and by increasing the standards of delivery rooms, delivery teams and neonatal intensive care units. Besides, early maternity cannot be underestimated; therefore raising the public awareness regarding early marriage is of particular importance.

The study also highlights the multifaceted problems relating to Cerebral Palsy which must be detected at the earliest to facilitate a timely and appropriate intervention. Finally, although CP is not a curable disease, rehabilitation, special educationand psycho-social support may significantly reduce the problems and may provide reintegration of the child into the community.

Funding:None.

Competing interests: None stated.

\section{References}

[1]. Rosenbaum P, Paneth N, Leviton A, Goldstein M, Bax M. A report: the definition and classification of Cerebral Palsy April 2006. Dev Med Child Neurol. 2007;109:8-14.

[2]. CDC. Data and Statistics for Cerebral Palsy.[ updated on: July 31, 2015] http://www.cdc.gov/ncbddd/cp/data.html

[3]. Jones Kathy. Incidence of Cerebral Palsy Remains Constant in India on Indian Health News. [Internet]. 2010.[updated on 2010 Oct 04; Accessed on 2013 Jan 22]. Available from: http://www.medindia.net/news/Incidence of Cerebral Palsy Remains Constant in India 749121.html .

[4]. Minear WL. A classification of Cerebral Palsy. Pediatrics 1956;18:841-52.

[5]. Behrman RE., Kliegman RM., Arvimn AM. Nelson Textbook of Pediatrics. 15th ed. Saunders. Philadelphia; 1996. Chapter 548, Cerebral Palsy; p.1713-14

[6]. Johnson A.Prevalance and Characteristics of Children with Cerebral Palsy in Europe. Developmental Medicine Child Neurology. 2002; 44: 633-640.

[7]. Laisram N, Srivastava VK and Srivastava RK. Cerebral Palsy-An Etiological Study. Indian Journal of Pediatrics. 1992;59:723728.

[8]. Gowda VK, Kumar A, Shivappa SK, Srikanteswara PK, Shivananda, Mahadeviah MS, Govindraj M, RamaswamyP. Clinical profile, predisposing factors, and associated co-morbidities of children with Cerebral Palsy in South India. J PediatrNeurosci. 2015 Apr-Jun; 10(2): 108-113

[9]. Bottos M, Granato T, Allibrio G, Gioachin C and Puato ML. Prevalence of Cerebral Palsy in North-East Italy from 1965 to 1989. Developmental Medicine Child Neurology. 1999; 41: 26-39.

[10]. Kavcic A and Perat MV. Prevalence of Cerebral Palsy in Slovenia: Birth Years 1981 to 1990. Developmental Medicine Child Neurology. 1998;40: 459-463.

[11]. Sharma P, Sharma U, Kabra A. Cerebral Palsy - Clinical profile and predisposing factors. Indian Pediatr. 1999; 36:1038-42.

[12]. Singhi P, Saini A.G. Changes in the Clinical Spectrum of Cerebral Palsy over Two Decades in North India-An Analysis of 1212 Cases. J Trop Pediatr. 2013; 59 (6): 434-440

[13]. Nelson KB, Ellenberg JH. Antecedents of Cerebral Palsy. Multivariate analysis of risk. N Engl J Med.1986 Jul 10;315(2):81-86.

[14]. Nelson KB, Grether JK. Causes of Cerebral Palsy. CurrOpinPediatr. 1999 Dec;11(6):487-91

[15]. Ozmen M, Calıskan M, Apak S and GokcayG. 8 Year Clinical Experience in Cerebral Palsy. Journal of Tropical Pediatrics. 1993; 39, 52-54.

[16]. Fraser AM, Brockert JE\&Ward RH. Association of young maternal age with adverse reproductive outcomes. N Engl J Med. 1995; 332:1113-7.

[17]. Wu YW, Croen LA, Shah SJ, Newman TB \&Najjar DV. Cerebral Palsy in a term population: risk factors and neuroimaging findings. Pediatrics. 2006; 118: 690-7.

[18]. ThorngrenJerneck, K. \& A. Herbst. Perinatal factors associated with Cerebral Palsy in children born in Sweden. Obstet Gynecol. 2006; 108: 1499-505.

[19]. Fidan F, Baysal O, Epidemiologic Characteristics of Patients with Cerebral Palsy. Open Journal of Therapy and Rehabilitation. 2014; $2: 126-132$

[20]. ZafeiriouDI, Kontopoulos EE, TsikoulasI. Characteristics and prognosis of epilepsy in children with Cerebral Palsy. J Child Neurol. 1999 May;14(5):289-94.

[21]. Singhi PD, Ray M, Suri G. Clinical Spectrum of Cerebral Palsy in North India-An Analysis of 1000 Cases. J Trop Pediatr. 2002; 48: 162-166.

[22]. Hoffer MM, Knoebel RT, Roberts R. Contractures in Cerebral Palsy. ClinOrthopRelat Res. 1987 Jun;(219):70-7. 